\title{
Respite care after acquired brain injury: the well-being of caregivers and patients
}

Citation for published version (APA):

Smeets, S. M., van Heugten, C. M., Geboers, J. F., Visser-Meily, J. M. A., \& Schepers, V. P. (2012).

Respite care after acquired brain injury: the well-being of caregivers and patients. Archives of Physical Medicine and Rehabilitation, 93(5), 834-841. https://doi.org/10.1016/j.apmr.2011.10.029

Document status and date:

Published: 01/05/2012

DOI:

10.1016/j.apmr.2011.10.029

Document Version:

Publisher's PDF, also known as Version of record

Document license:

Taverne

Please check the document version of this publication:

- A submitted manuscript is the version of the article upon submission and before peer-review. There can be important differences between the submitted version and the official published version of record.

People interested in the research are advised to contact the author for the final version of the publication, or visit the DOI to the publisher's website.

- The final author version and the galley proof are versions of the publication after peer review.

- The final published version features the final layout of the paper including the volume, issue and page numbers.

Link to publication

\footnotetext{
General rights rights.

- You may freely distribute the URL identifying the publication in the public portal. please follow below link for the End User Agreement:

www.umlib.nl/taverne-license

Take down policy

If you believe that this document breaches copyright please contact us at:

repository@maastrichtuniversity.nl

providing details and we will investigate your claim.
}

Copyright and moral rights for the publications made accessible in the public portal are retained by the authors and/or other copyright owners and it is a condition of accessing publications that users recognise and abide by the legal requirements associated with these

- Users may download and print one copy of any publication from the public portal for the purpose of private study or research.

- You may not further distribute the material or use it for any profit-making activity or commercial gain

If the publication is distributed under the terms of Article $25 \mathrm{fa}$ of the Dutch Copyright Act, indicated by the "Taverne" license above, 
ORIGINAL ARTICLE

\title{
Respite Care After Acquired Brain Injury: The Well-Being of Caregivers and Patients
}

\author{
Sanne M. Smeets, MSc, Caroline M. van Heugten, PhD, Johanna F. Geboers, MD, PhD, \\ Johanna M. Visser-Meily, MD, PhD, Vera P. Schepers, MD, PhD
}

ABSTRACT. Smeets SM, van Heugten CM, Geboers JF, Visser-Meily JM, Schepers VP. Respite care after acquired brain injury: the well-being of caregivers and patients. Arch Phys Med Rehabil 2012;93:834-41.

Objective: To investigate satisfaction with respite care, the well-being of informal caregivers and patients with acquired brain injury (ABI) who receive respite care by day-care activity centers, and factors related to caregiver well-being.

Design: Cross-sectional cohort study.

Setting: Adult day-care activity centers.

Participants: A sample of caregivers and patients $(\mathrm{N}=108)$ with ABI (mean of 8y since injury) enrolled in 1 of 7 day-care activity centers. The sample consisted predominantly (70\%) of stroke patients.

Intervention: Respite care by adult day-care activity centers.

Main Outcome Measures: Well-being was defined in terms of life satisfaction (Life Satisfaction Questionnaire [LiSat-9]), emotional functioning (Hospital Anxiety and Depression Scale [HADS]), and caregiver burden (Caregiver Strain Index [CSI]). Factors related to well-being were personal, injury related, and psychological.

Results: Satisfaction with day-care activity center care was high for caregivers (7.8) and patients (8.1). Caregiver satisfaction with care was unrelated to caregiver well-being. Most caregivers $(61 \%)$ showed low life satisfaction and high subjective burden (69\%), and $33 \%$ of caregivers and $42 \%$ of the patients reported depressive symptoms. Caregiver well-being was positively correlated with a high sense of mastery of caregivers and patients and low passive coping of the patient (LiSat-9 $R^{2}=.32$; HADS $R^{2}=.55$; CSI $\left.R^{2}=.35\right)$.

Conclusions: This study emphasizes the need for care for both caregivers and patients in the chronic phase after ABI. Although respite care is highly appreciated, it is not sufficient for caregivers to attain a healthy level of well-being. Results indicate that caregiver well-being might improve by targeting passive coping and mastery skills of caregivers and patients. Continuous support for both caregivers and patients is needed.

From the School for Mental Health and Neuroscience, Department of Psychiatry and Neuropsychology (Smeets, van Heugten) and Department of Neuropsychology and Psychopharmacology (van Heugten), Maastricht University, Maastricht; Limburg Foundation for Care for the Disabled (SGL) Rehabilitation Center, Heerlen (Geboers); and Rudolf Magnus Institute of Neuroscience and Center of Excellence for Rehabilitation Medicine, University Medical Center Utrecht and De Hoogstraat, Utrecht (Visser-Meily, Schepers), The Netherlands.

No commercial party having a direct financial interest in the results of the research supporting this article has or will confer a benefit on the authors or on any organization with which the authors are associated.

Reprint requests to Caroline M. van Heugten, $\mathrm{PhD}$, School for Mental Health and Neuroscience (MHeNS), Dept of Psychiatry and Neuropsychology, Maastricht University, PO Box 6166200 MD Maastricht, The Netherlands, e-mail: c.vanheugten@maastrichtuniversity.nl.

In-press corrected proof published online on Mar 9, 2012, at www.archives-pmr.org.

0003-9993/12/9305-00886\$36.00/0

doi:10.1016/j.apmr.2011.10.029
Key Words: Brain injuries; Caregivers; Quality of life; Rehabilitation; Respite care.

(C) 2012 by the American Congress of Rehabilitation Medicine

TFORMAL CAREGIVERS PLAY an important role in the practical and emotional support of patients with acquired brain injury (ABI). Providing care for these patients is a serious matter and can lead to high levels of burden and deterioration in quality of life and psychosocial functioning of the caregivers themselves long after the onset of brain injury. ${ }^{1-3}$ Therefore, caregivers often indicate that they need time and activities for themselves outside the home. ${ }^{4,5}$

The results of caregiver studies have stressed the need for interventions specifically aimed at their well-being. Respite care services are an example of such interventions. Respite care is a general term for different types of organized support services that are aimed at temporarily relieving informal caregivers of their caretaking responsibility to ease their burden. ${ }^{5-7}$ There are a variety of respite care services such as day care, in-home respite care, weekend lodging, respite hospitalization, and caregiver support groups. ${ }^{6,7}$ Services such as day-care and activity centers are used as a form of relief for caregivers and can also provide leisure or social activities $^{8-10}$ to ABI patients themselves.

Respite care has been the subject of various studies. One line of research has investigated general attitudes and preferences of informal caregivers toward respite care. ${ }^{6,7,11}$ In 1 study, ${ }^{6}$ $32 \%$ of the respondents were already using respite care, and both caregivers and patients were quite satisfied with the care they received. Other studies ${ }^{6,7,11}$ have shown that $53 \%$ to $69 \%$ of informal caregivers who do not use respite care desired to. Caregivers who would like to use respite care have a relatively high subjective burden. Most of these caregivers expected that this burden would decrease if they used respite care. ${ }^{6}$

The effect of respite care on caregivers has been studied mainly in the (frail) elderly and in patients with dementia. Systematic reviews of these studies have revealed evidence for positive effects of respite care on caregivers. However, most of the studies had poor methodological quality. ${ }^{12-14}$ Little research has been done on respite care specifically for caregivers of patients with ABI. One of these few studies is the study by Chan. ${ }^{5}$ By using a survey he has investigated the perspectives of caregivers of $\mathrm{ABI}$

\section{List of Abbreviations}

$\begin{array}{ll}\text { ABI } & \text { acquired brain injury } \\ \text { CFO } & \text { Cognitive Failures Questionnaire } \\ \text { CSI } & \text { Caregiver Strain Index } \\ \text { HADS } & \text { Hospital Anxiety and Depression Scale } \\ \text { LiSat-9 } & \text { Life Satisfaction Questionnaire } \\ \text { MRS } & \text { Modified Rankin Scale } \\ \text { UCL-P } & \text { Utrecht Coping List Passive reactions scale } \\ \text { UCO } & \text { Utrecht Communication Observation }\end{array}$


patients toward respite care. He found that caring interfered with obtaining paid work and highlighted this group's need for respite care. ${ }^{5}$ Respite care services for caregivers of patients with ABI are offered in The Netherlands in several forms. One form is the day-care activity center, where patients engage in supervised activities during the day, which allows caregivers to be relieved from their caretaking responsibilities. Patients are often enrolled in these day-care activity centers for several years.

The well-being of caregivers and patients who are in the chronic phase after injury ( $>1$ y postinjury) and who receive this specific type of long-term respite care remains unexplored. However, it is an important form of care for caregivers of patients with $\mathrm{ABI}$, who can experience high levels of burden and reduced quality of life and psychosocial functioning. ${ }^{1-3}$ Therefore, in the present study, we investigated the following research questions: (1) How satisfied are caregivers and patients with the care offered by the day-care activity center? (2) What is the level of well-being of caregivers and patients who participate in day-care activity centers? (For the purpose of this study, the parameters of well-being are considered to be life satisfaction, emotional functioning, and caregiver burden.) (3) Which factors are associated with caregivers' well-being? (These factors include general and psychological characteristics of the caregiver and patient, and patient injury-related characteristics.) The aim of the final research question was to explore whether the aforementioned characteristics should be taken into consideration in the development of adequate health care services and respite care programs in the future.

\section{METHODS}

\section{Participants}

Participants were recruited on the basis of participation in 1 of 7 day-care activity centers that were located in 2 different regions in The Netherlands. Four were located in the southern region (Limburg Foundation for Care for the Disabled [SGL] centers), and 3 were located in the middle of the country (Boogh centers). Participants included both patients and their caregivers. Patients were included if they were 18 years or older, sustained an ABI after the age of 18, attended 1 of the day-care activity centers 1 or more days a week, and were living independently in the community together with a partner or child. Patients were excluded if they had severe aphasia or other language problems (eg, difficulties with reading or insufficient command of the Dutch language) or had a psychiatric disorder (eg, major depression, psychosis). Information on aphasia and psychiatric conditions was acquired from the patients' medical records. Caregivers were included when they shared a household with the patient and were considered to be the primary caregiver.

\section{Respite Care}

The respite care offered in this study was an adult activity day care, provided in an adult day-care activity center. The center provides care for adults with physical disabilities, ABI, or both. The day-care activity center is a nonresidential facility providing recreational activities with professional support, social stimulation, and general supervision 1 or more days a week. Specific activities may include painting, baking/cooking, farm activities, fitness, yoga, computer workshops, or assembly work

\section{Procedure}

Day-care activity center participants were identified via a search of the available data in 2 participating organizations
Table 1: Satisfaction With the Day-Care Activity Center Statements

Caregivers' perspective

1. Participation in the day-care activity center gives my partner a boost.

2. My partner's participation in the day-care activity center relieves me from my care duties.

3. I would like to be more involved in the activities of the center.

4. It is good for my partner that I have activities of my own.

5 . I would recommend participation in the day-care activity center to people who are in the same situation.

Patients' perspective

1. Participation in the day-care activity center is a good way to be pleasantly busy during the day.

2. The activities fit my interests sufficiently.

3. The supporting care of the day-care activity center is capable of helping and stimulating me.

4. It is good for my partner that I have activities of my own.

5. I would recommend participation in the day-care activity center to people who are in the same situation.

NOTE. Statements were graded on a scale from 0 (completely disagree) to 10 (completely agree).

(SGL and Boogh). Patients who met the inclusion criteria were selected and sent a letter by mail that explained the goal of the research study. Two sets of questionnaires were enclosed with the letter: one for the patient and one for the caregiver. Patients and caregivers could call a research assistant for help in completing the questionnaires or could receive assistance at the day-care activity center. If questionnaires were not returned within 2 weeks, a research assistant contacted the patient by telephone. By returning the questionnaires, patients and caregivers consented to participation. The responsible institutional research review boards approved the procedures.

In addition, staff members of the day-care activity center completed 2 questionnaires about the patients' functioning.

\section{Measurements}

Day-care activity center-related information. Caregivers' and patients' satisfaction with the day-care activity center was measured with 5 statements (table 1) that were graded on a scale from 0 (completely disagree) to 10 (completely agree). This questionnaire was developed specifically for this study by the authors. In addition, patients provided the following information regarding day-care activity center participation: referral information, time since starting the day-care activities, and number of days per week that they participated in the center.

Demographic information. The questionnaire sets for both caregivers and patients included questions regarding demographic information (sex, age, educational level). Educational level was rated on a 5-point scale with the following categories: (1) primary education; (2) lower vocational education; (3) lower general secondary education; (4) higher general secondary education/preuniversity education; and (5) higher vocational education/university. In addition, the patients were asked about their premorbid employment status, which was classified into the following 5 categories: (1) paid and full-time; (2) paid and part-time; (3) volunteer work; (4) student; and (5) no (un)paid job.

ABI characteristics. Patients answered questions about their injury including type of ABI, years since brain injury, and discharge information. Brain injury was divided into the following types: stroke, brain tumor, traumatic brain injury, and 
other (eg, hypoxia, intoxication). Discharge information included the following options: discharged home from a hospital, rehabilitation center, or nursing home. The Cognitive Failures Questionnaire $(\mathrm{CFQ})^{15}$ was administered to the patients to measure the level of cognitive functioning. This self-report scale assesses failures in perception, memory, and motor function, and the internal consistency of the Dutch version is high $(\alpha=.88){ }^{16}$ Scores range from 0 to 100 , with higher scores indicating more problems with cognitive functioning. ${ }^{17}$ Furthermore, staff members of the day-care activity centers scored the Modified Rankin Scale (MRS) ${ }^{18}$ to obtain a handicap score on a 6-point scale from 1 (no symptoms) to 6 (severe handicap). The scale has a moderate interrater reliability $(\kappa=.78)$ in stroke samples. ${ }^{19}$ Staff members also completed the Utrecht Communication Observation (UCO) to indicate the communication skills of the patient on a 5-point scale ranging from 1 (no communication possible) to 5 (normal communication). ${ }^{20}$

Well-being. Two self-report questionnaires were used to assess caregiver and patient well-being. The Life Satisfaction Questionnaire (LiSat-9) was used to measure perceived life satisfaction. $^{21}$ This scale consists of 9 questions addressing satisfaction with life in general, ability to manage self-care, leisure, vocation/occupation, financial situation, sex life, partner relationship, family life, and contacts with friends and acquaintances. Answers are rated on a 6-point scale from 1 (very dissatisfying) to 6 (very satisfying), with higher scores indicating higher satisfaction with life. The item responses were dichotomized into satisfied (5-6) and dissatisfied (1-4). The Dutch translation of the LiSat-9 has been used in stroke patients, and the reliability is satisfactory to good $(\alpha=.74-$ $.82) .{ }^{22,23}$ Emotional functioning was measured with the Dutch Hospital Anxiety and Depression Scale (HADS), ${ }^{24,25}$ a 14 -item measure with 7 items relating to the anxiety subscale and 7 items to the depression subscale. A score of 7 or higher on each subscale indicates a clinically relevant increased level of depressive or anxiety symptoms, or both. The Dutch version of the HADS has been validated in several samples (general, psychiatric, and medical). ${ }^{25}$ The internal consistency of the total scale is good $(\alpha=.84-.90)$, as is the internal consistency of the anxiety $(\alpha=.80-.84)$ and depression $(\alpha=.71-.86)$ subscales. $^{25}$

Caregiver burden was assessed with the Caregiver Strain Index (CSI). ${ }^{26}$ This is a brief questionnaire of 13 yes/no items completed by the caregiver to measure subjective burden. Seven or more positive items indicate a high burden level. The internal consistency of the scale is good $(\alpha=.86){ }^{26}$

Psychological characteristics. Caregivers and patients received questionnaires regarding coping and sense of mastery. The Utrecht Coping List Passive reactions scale (UCL-P) ${ }^{27,28}$ was used to measure passive coping. It consists of 7 items, and higher scores indicate more use of passive coping styles (range, $7-28$ ). In the Dutch general population, the internal consistency of the UCL-P is moderate $(\alpha=.74){ }^{28}$ Sense of mastery over one's life was assessed with the Mastery Scale. ${ }^{29}$ The total score on the 7 items of this self-report questionnaire ranges from 0 to 35, with higher scores indicating a greater sense of mastery over one's life. In a sample of informal caregivers of stroke survivors, the scale had a good internal consistency $(\alpha=.86){ }^{30}$

\section{Statistical Analyses}

The mean of the answers on the aforementioned respite care satisfaction questionnaire was computed. Descriptive statistics (frequencies and means) were used to analyze the demographic characteristics of caregivers and patients, and patient injury characteristics. Educational level was dichotomized into low educational level (levels 1 through 3 ) and high educational level (levels 4 and 5). The type of brain injury was dichotomized into stroke versus nonstroke because of the high number of stroke patients in the sample and to minimize the number of levels of the predictor. Because the data were not normally distributed, differences in life satisfaction scores between caregivers and patients were tested with the nonparametric MannWhitney $U$ test. The relationship between caregiver and patient characteristics and caregiver well-being (life satisfaction, emotional functioning, and burden) was investigated with linear regression analyses. To identify which caregiver and patient variables were related to the dependent variables, the Pearson correlation of each combination was calculated. The dependent caregiver variables LiSat-9, HADS, and CSI were correlated to the following independent patient variables: sex, age, educational level, type of brain injury, time since injury, CFQ, MRS, UCO, LiSat-9, HADS, UCL-P, Mastery Scale, time since start of day-care activities, days a week attending the day-care activity center, and satisfaction with the day-care activity center. Independent caregiver variables included age, sex, educational level, UCL-P, Mastery Scale, and satisfaction with the day-care activity center. Independent variables that correlated significantly $(P \leq .05)$ with one of the dependent variables were used to build a regression model per dependent variable using the stepwise backward method. Because this is one of the first studies investigating respite care and well-being of caregivers of ABI patients, we chose the stepwise backward method to explore the associations.

Assumptions for regression analyses were checked. SPSS for Mac version $18^{\mathrm{a}}$ was used, and alpha was set at .05 .

\section{RESULTS}

\section{Caregiver and Patient Characteristics}

In total, 295 patients from the 7 respite care centers and their caregivers met the inclusion criteria and were approached to participate in the study, and 150 completed questionnaires were received. More patients than caregivers returned the questionnaires (150 vs 108). For the present study, only those cases for which both caregiver and patient data were available were included. This resulted in 108 pairs of patients and caregivers, of which 104 pairs were partners, 3 pairs were parent/child, and 1 pair had an unknown relationship. Demographic information of both caregivers and patients is shown in table 2. Most patients were men, while most caregivers were women. About $71 \%$ of the patients had a paid job before the ABI.

ABI characteristics of the patients are shown in table 2 . Stroke was the main cause of brain injury (nearly $70 \%$ ). After the injury, most patients were discharged home from a rehabilitation center $(67 \%)$ or a hospital $(24.5 \%)$, with a minority discharged from a nursing home $(8.5 \%)$. Twenty-eight percent of the patients had serious communication problems (UCO), and more than $80 \%$ were moderately to severely disabled (MRS). The patients reported more cognitive problems (CFQ) in comparison with a healthy Dutch control sample. ${ }^{16}$

\section{Participation In and Satisfaction With the Day-Care Activity Center}

Patients in this study had participated in respite care at a day-care activity center for an average \pm SD of $4.8 \pm 4.2$ years, and most patients visited the center $2(40.6 \%)$ or $3(39.6 \%)$ days a week. In addition, the day-care activity center was visited 1 day a week by $6.6 \%$ of the patients, 4 days by $10.4 \%$, and 5 days by $2.8 \%$. Referral to the day-care activity center was mostly made by a rehabilitation center $(57.3 \%)$, and $6.8 \%$ of 
Table 2: Characteristics of Caregivers and Patients With ABI

\begin{tabular}{|c|c|c|}
\hline Characteristics & Caregivers & Patients \\
\hline \multicolumn{3}{|l|}{ General characteristics } \\
\hline Sex (men) & 25 & 74.1 \\
\hline Age (y) & $58.9 \pm 10.8$ & $61.3 \pm 9.3$ \\
\hline \multicolumn{3}{|l|}{ Educational level } \\
\hline Elementary education & 13.9 & 15.7 \\
\hline Vocational training & 39.8 & 42.6 \\
\hline $\begin{array}{l}\text { Lower general secondary } \\
\text { education }\end{array}$ & 25.9 & 24.1 \\
\hline $\begin{array}{l}\text { Higher general } \\
\text { secondary/preuniversity } \\
\text { education }\end{array}$ & 6.5 & 8.3 \\
\hline $\begin{array}{l}\text { Higher vocational education/ } \\
\text { university }\end{array}$ & 13.9 & 9.3 \\
\hline \multicolumn{3}{|l|}{$\begin{array}{l}\text { Patient premorbid employment } \\
\text { status }\end{array}$} \\
\hline Paid and full-time & & 60.2 \\
\hline Paid and part-time & & 11.1 \\
\hline Voluntary work & & 3.7 \\
\hline Student & & 13.9 \\
\hline No (un)paid job & & 11.1 \\
\hline \multicolumn{3}{|l|}{ Patient $\mathrm{ABI}$ characteristics } \\
\hline \multicolumn{3}{|l|}{ Type of ABI } \\
\hline Left hemispheric stroke & & 34.3 \\
\hline Right hemispheric stroke & & 35.2 \\
\hline Brain tumor & & 4.7 \\
\hline Traumatic brain injury & & 8.3 \\
\hline Other & & 17.6 \\
\hline Years since brain injury & & $8 \pm 7.1(1-42)$ \\
\hline CFO $(n=91)$ & & $43.7 \pm 17.8$ \\
\hline \multicolumn{3}{|l|}{ UCO $(n=93)$} \\
\hline Client cannot communicate & & 0 \\
\hline $\begin{array}{l}\text { Some communication possible } \\
\text { (eg, yes/no, facial } \\
\text { expressions) }\end{array}$ & & 10.8 \\
\hline $\begin{array}{l}\text { Communication possible with } \\
\text { help from test leader }\end{array}$ & & 17.2 \\
\hline $\begin{array}{l}\text { Communication about } \\
\text { everyday things of life, with } \\
\text { little help }\end{array}$ & & 34.4 \\
\hline $\begin{array}{l}\text { Communication possible about } \\
\text { many subjects, almost } \\
\text { without help }\end{array}$ & & 37.6 \\
\hline \multicolumn{3}{|l|}{$\operatorname{MRS}(n=93)$} \\
\hline No symptoms & & 0 \\
\hline Symptoms but not disabled & & 3.2 \\
\hline Slightly disabled & & 15.1 \\
\hline Moderately disabled & & 29.0 \\
\hline Moderate severely disabled & & 38.7 \\
\hline Severely disabled & & 14.0 \\
\hline \multicolumn{3}{|l|}{ Psychological characteristics } \\
\hline UCL-P & $11.8 \pm 3.6$ & $12.7 \pm 4.2$ \\
\hline Mastery Scale & $22.7 \pm 4.9$ & $19.2 \pm 5.5$ \\
\hline
\end{tabular}

NOTE. Values are percentages, mean $\pm S D$, or mean \pm SD (range). $\mathrm{N}=108$ unless otherwise specified.

patients with ABI were referred by social services. Other referral organizations were general practitioners or home care organizations $(28.1 \%)$. In $7.8 \%$ of the cases, patients referred themselves.

Table 3 presents the satisfaction with the day-care activity center from both the caregivers' and the patients' perspectives. In general, caregivers and patients were satisfied with the care (mean grades ranged from 7.6 to 8.8 ). Only the caregivers' involvement in day-care center activities received a low average grade (5.3). The satisfaction with the day-care activity center was not associated with the number of years participating in the activity center $(R=.15 ; P=.13)$.

\section{Caregiver and Patient Well-Being}

Results of the LiSat-9 for caregivers and patients are shown in table 4. Most caregivers $(60.7 \%)$ and patients $(59.6 \%)$ were not satisfied with their life as a whole. Caregivers were least satisfied with their sex life $(78.9 \%)$ and most satisfied with their self-care abilities $(87.5 \%)$. Patients were least satisfied with their sex life $(78.5 \%)$ and their vocational situation $(69.7 \%)$. Caregivers were significantly more satisfied with their self-care abilities and leisure activities than patients. Patients were significantly less satisfied with their vocational situation than caregivers, whereas caregivers were significantly less satisfied with their partner relationship.

On the HADS depression scale, $33.3 \%$ of the caregivers scored above the cutoff point (mean \pm SD: $6.28 \pm 4.22$ ), and $40.2 \%$ had a score above the cutoff point for anxiety (7.20 \pm 3.95$)$. The total mean score \pm SD of the HADS was 13.48 \pm 7.60. The patients' mean HADS score \pm SD was $13.07 \pm 7.07$, and $42 \%$ scored above the cutoff for depression (7.37 \pm 4.32 ), while $27.3 \%$ scored above the cutoff for anxiety (5.86 44.98$)$.

The mean CSI score \pm SD was $8.24 \pm 2.88$, with $69 \%$ of the caregivers reporting a high burden.

\section{Relationships Between Caregiver and Patient Characteristics and Caregiver Well-Being}

Correlations between the 3 caregiver well-being variables and caregiver and patient characteristics are shown in table 5 . A caregiver's LiSat-9 score correlated significantly with their respective patient's LiSat-9 and UCL-P scores, and with their own UCL-P and Mastery Scale scores. Caregiver HADS scores were related to their education level, Mastery Scale, UCL-P score, and patient LiSat-9, HADS, and UCL-P scores. Furthermore, caregiver CSI scores were associated with their Mastery Scale and UCL-P scores, and with the patient's MRS, UCO, LiSat-9, HADS, UCL-P, and Mastery Scale scores.

Table 3: Caregiver and Patient Satisfaction With the Day-Care Activity Center

\begin{tabular}{lcc}
\hline \multicolumn{1}{c}{ Statements } & $\mathrm{n}$ & Mean* \pm SD \\
\hline Caregivers' perspective & & \\
1. Boost for partner & 108 & $8.5 \pm 1.4$ \\
2. Relief from care duties & 107 & $8.2 \pm 2.0$ \\
3. More involvement & 100 & $5.3 \pm 2.9$ \\
4. Good for partner that I & 103 & $8.2 \pm 1.7$ \\
$\quad$ have my own activities & & \\
5. Recommend participation & 107 & $8.8 \pm 1.4$ \\
Patients' perspective & & \\
1. Good way to be pleasantly & 105 & $8.2 \pm 1.6$ \\
$\quad$ busy & 100 & $7.6 \pm 2.0$ \\
2. Fit interests & 103 & $8.0 \pm 1.6$ \\
3. Care is helpful and & & \\
$\quad$ stimulating & 101 & $8.8 \pm 1.2$ \\
4. Good for partner that I & & \\
$\quad$ have my own activities & 100 & $8.5 \pm 1.7$
\end{tabular}

*Mean represents the average grade granted to the statement, with a range from 0 (completely disagree) to 10 (completely agree). 
Table 4: Life Satisfaction of Caregivers and Patients

\begin{tabular}{|c|c|c|c|c|c|c|c|c|c|}
\hline \multirow[b]{2}{*}{ LiSat-9 Item } & \multicolumn{4}{|c|}{ Caregivers } & \multicolumn{4}{|c|}{ Patients } & \multirow[b]{2}{*}{$U$} \\
\hline & $\mathrm{n}$ & $\%$ Dissatisfied & Mean $\pm S D$ & Median & $\mathrm{n}$ & $\%$ Dissatisfied & Mean $\pm \mathrm{SD}$ & Median & \\
\hline Life as a whole & 107 & 60.7 & $4.1 \pm 1.1$ & 4 & 104 & 59.6 & $4.0 \pm 1.2$ & 4 & 5610.5 \\
\hline Self-care & 104 & 12.5 & $5.3 \pm 1.3$ & 6 & 103 & 64.1 & $3.8 \pm 1.5$ & 4 & $8651.0 *$ \\
\hline Leisure & 107 & 44.9 & $4.6 \pm 1.0$ & 5 & 103 & 56.3 & $4.2 \pm 1.0$ & 4 & $6612.0^{+}$ \\
\hline Vocational situation & 102 & 45.1 & $4.4 \pm 1.1$ & 5 & 89 & 69.7 & $3.2 \pm 1.6$ & 3 & $6424.5^{*}$ \\
\hline Financial situation & 106 & 50.0 & $4.3 \pm 1.0$ & 4 & 101 & 58.4 & $4.0 \pm 1.3$ & 4 & 6048.0 \\
\hline Sexual life & 95 & 78.9 & $3.1 \pm 1.4$ & 3 & 93 & 78.5 & $3.0 \pm 1.6$ & 3 & 4597.0 \\
\hline Partnership relations & 106 & 43.4 & $4.3 \pm 1.4$ & 5 & 98 & 27.6 & $5.0 \pm 1.0$ & 5 & $3812.5^{*}$ \\
\hline Family life & 104 & 36.5 & $4.7 \pm 1.1$ & 5 & 102 & 30.4 & $4.8 \pm 1.1$ & 5 & 4921.5 \\
\hline Contact with friends & 107 & 39.3 & $4.4 \pm 1.2$ & 5 & 105 & 47.6 & $4.3 \pm 1.3$ & 5 & 5893.5 \\
\hline
\end{tabular}

Mann-Whitney $U$ test (difference between caregivers and patients): ${ }^{*} P \leq .001 ;{ }^{\dagger} P \leq .05$.

\section{Multiple Regression of Caregiver and Patient Characteristics and Caregiver Well-Being}

The data met the assumptions for multiple regression analysis. No collinear relationships were identified. The 3 final regression models are shown in table 6. A higher life satisfaction (LiSat-9 $R^{2}=.32$ ) for the caregiver was significantly associated with a higher life satisfaction of the patient $(\beta=.25)$ and an increased sense of mastery of the caregiver $(\beta=.44)$. Low depression and anxiety symptoms of the caregiver (HADS $\left.R^{2}=.55\right)$ were significantly related to less passive coping $(\beta=.42)$ and a higher sense of mastery of the caregiver $(\beta=-.30)$. For the final model, lower caregiver burden (CSI $\left.R^{2}=.35\right)$ was significantly predicted by higher patient handicap severity $(\beta=.17)$ and by a higher sense of mastery of both the caregiver and patient $(\beta=-.39$ and -.30 , respectively).

\section{DISCUSSION}

The results of this study show that caregivers and patients in the chronic phase after ABI were satisfied with the respite care offered by day-care activity centers. However, most caregivers and patients were not satisfied with their life as a whole. The subjective burden of caregivers was high (69\%), with $40 \%$ experiencing anxiety symptoms and $33 \%$ showing depressive symptoms. The high level of caregiver burden might be a reflection of the impact of $\mathrm{ABI}$ on life, which might be extensive in this sample because the patients were young and active at the time of injury. (Notably, $71 \%$ of patients were working before the ABI.) It is possible that caregiver burden will always exist and can only be partially relieved. We found that caregiver well-being can be predicted by psychological characteristics of both caregivers and patients

Table 5: Correlations Between Patient Variables and Caregiver Variables and the Outcome Measures

\begin{tabular}{|c|c|c|c|c|c|c|}
\hline \multirow[b]{2}{*}{ Variables } & \multicolumn{2}{|c|}{$\begin{array}{l}\text { LiSat-9 Total } \\
\text { Caregiver }\end{array}$} & \multicolumn{2}{|c|}{$\begin{array}{l}\text { HADS Total } \\
\text { Caregiver }\end{array}$} & \multicolumn{2}{|c|}{ CSI } \\
\hline & $r$ & $\mathrm{n}$ & $r$ & $\mathrm{n}$ & $r$ & $\mathrm{n}$ \\
\hline \multicolumn{7}{|l|}{ Patient variables } \\
\hline Sex & -.009 & 97 & -.022 & 107 & .076 & 100 \\
\hline Age & -.058 & 97 & .114 & 107 & .144 & 100 \\
\hline Educational level & .011 & 97 & -.120 & 107 & .068 & 100 \\
\hline Type of ABI & .041 & 97 & -.163 & 107 & -.101 & 100 \\
\hline Time since injury & .039 & 92 & -.096 & 102 & -.038 & 95 \\
\hline CFO & -.024 & 81 & .101 & 90 & .051 & 86 \\
\hline MRS & -.011 & 84 & .011 & 92 & $.301 *$ & 86 \\
\hline UCO & -.074 & 84 & -.051 & 92 & $-.259^{*}$ & 86 \\
\hline LiSat-9 total & $.478^{\ddagger}$ & 83 & $-.370^{\ddagger}$ & 88 & $-.448^{\ddagger}$ & 83 \\
\hline HADS total & -.145 & 88 & $.210^{\dagger}$ & 98 & $.236^{\dagger}$ & 91 \\
\hline UCL-P total & $-.271 *$ & 90 & $.271 *$ & 98 & $.234^{\dagger}$ & 92 \\
\hline Mastery Scale total & .097 & 87 & -.163 & 94 & $-.438^{\ddagger}$ & 89 \\
\hline Time since start of respite care & -.007 & 91 & -.037 & 99 & .110 & 92 \\
\hline Days per week of respite care & -.166 & 96 & .085 & 105 & .133 & 98 \\
\hline Satisfaction with of respite care & .074 & 94 & .038 & 104 & .057 & 98 \\
\hline \multicolumn{7}{|l|}{ Caregiver variables } \\
\hline Age & -.029 & 97 & .156 & 107 & .116 & 100 \\
\hline Sex & .005 & 97 & .040 & 107 & -.051 & 102 \\
\hline Educational level & .145 & 97 & $-.231^{\dagger}$ & 107 & -.043 & 100 \\
\hline UCL-P total & $-.398^{\ddagger}$ & 92 & $.677^{ \pm}$ & 101 & $.349^{\ddagger}$ & 97 \\
\hline Mastery Scale total & $.530^{\ddagger}$ & 95 & $-.642^{\ddagger}$ & 104 & $-.476^{\ddagger}$ & 97 \\
\hline Satisfaction with respite care & .114 & 97 & .059 & 107 & .173 & 100 \\
\hline
\end{tabular}

Pearson correlation: ${ }^{*} P<.01 ;{ }^{\dagger} P<.05 ;{ }^{\ddagger} P<.001$ (2-tailed). 
Table 6: Final Regression Models

\begin{tabular}{|c|c|c|c|c|c|}
\hline Variables & B & SE B & $\beta$ & $R^{2}$ & 95\% Confidence Interval \\
\hline LiSat-9 total score caregiver & & & & .32 & \\
\hline Constant & 1.852 & .385 & & & \\
\hline LiSat-9 total score patient & .256 & .087 & $.25^{*}$ & & .08 to .43 \\
\hline Mastery Scale total score caregiver & .065 & .012 & $.44^{+}$ & & .04 to .09 \\
\hline HADS total score caregiver & & & & .55 & \\
\hline Constant & 24.52 & 5.41 & & & \\
\hline LiSat-9 total score patient & -1.86 & 0.76 & $-.17^{ \pm}$ & & -3.37 to -.35 \\
\hline UCL-P total score caregiver & .91 & .19 & $.42^{+}$ & & .54 to 1.27 \\
\hline Mastery Scale total score caregiver & -.47 & .14 & $-.30^{\dagger}$ & & -.75 to -.20 \\
\hline Educational level caregiver & -2.98 & 1.24 & $-.16^{\ddagger}$ & & -5.43 to -.52 \\
\hline CSI & & & & .35 & \\
\hline Constant & 14.64 & 1.61 & & & \\
\hline MRS & .51 & .24 & $.17^{\ddagger}$ & & .04 to .98 \\
\hline Mastery Scale total score patient & -.16 & .04 & $-.30^{\dagger}$ & & -.25 to -.07 \\
\hline Mastery Scale total score caregiver & -0.22 & 0.05 & $-.39^{\dagger}$ & & -32 to -.13 \\
\hline
\end{tabular}

NOTE. Missing values were replaced with the variable mean. Stepwise backward, removal of variable if $P>05$.

${ }^{*} P<.01 ;{ }^{\dagger} P<.001 ;{ }^{\ddagger} P<.05$.

but not by ABI or day-care activity center characteristics. Only caregiver burden was predicted by the severity of physical disabilities of the patient.

Besides high levels of burden, $33 \%$ of the caregivers showed depressive symptoms, and most experienced low life satisfaction, because respite care offered by the day-care activity center did not completely relieve caregivers. Additional help might be found in interventions aimed at coping and mastery skills. Caregivers who felt in control of their lives were more satisfied with life, felt less strained, and showed fewer symptoms of depression and anxiety. In addition, caregivers who used a less passive coping style showed better emotional functioning. Persons with a tendency to use passive coping mechanisms do not take any action when problems occur, ${ }^{23}$ and this strategy seems detrimental to emotional functioning. This result is comparable to those of other studies, ${ }^{23,31-33}$ which found relationships between aspects of coping and depression. Patient variables appeared to predict caregiver outcome as well. The patients' life satisfaction positively influenced the life satisfaction of their caregivers. Furthermore, caregivers experienced a smaller burden if the patients had a high sense of mastery.

In our study, patients were discharged despite considerable disabilities ( $81 \%$ were moderately to severely disabled). Although caregivers and patients had been receiving respite care for several years, they were still struggling with the consequences of brain injury. Chronic care for these patients is rarely offered, and no procedures for care are specified. Only $10 \%$ to $20 \%$ of the patients in this sample were referred to social work, a psychologist, or both, after discharge from acute care facilities. The long-term problems of patients with brain injuries and their caregivers should be acknowledged and incorporated in regular care.

Furthermore, the results of the LiSat-9 showed that both caregivers and patients were dissatisfied with their sexual life $(78.9 \%$ and $78.5 \%$, respectively), and caregivers were significantly less satisfied with the relationship with their partner than the patients were. These results might reflect a changed relationship as a consequence of brain injury and the subsequent low well-being of the caregiver. Besides targeting interventions at coping and mastery skills, therapies addressing the caregiver/patient relationship might also be beneficial. ${ }^{2,10}$
The finding that both patients and caregivers were satisfied with the care offered by the activity day-care center agrees with a previous study ${ }^{6}$ that investigated satisfaction with respite care in general. Although $33 \%$ of the caregivers experienced depressive symptoms, this rate was less than those found in studies ${ }^{23,33}$ evaluating caregivers of patients 1 year after injury (50\%-52\%). Like others, we did not find associations between individual characteristics (eg, age and sex) of caregivers and quality of life. ${ }^{23,34}$

The results of this study suggest that for better caregiver functioning, interventions should target mastery and coping skills of both caregivers and patients. This idea was recently studied by Backhaus et al, ${ }^{35}$ who investigated a brain injury coping skills group treatment for caregivers and patients in the first year after brain injury. The randomized controlled pilot study yielded promising results, reporting an improvement in self-efficacy for the experimental treatment group. However, because the intervention took place within the first year after the injury, it was aimed at preventing future problems. In the current study, patients were already in the chronic phase of their injury, and a more constructive approach in this group should stress self-management of the consequences of brain injury and continuous support for both caregivers and patients. Consequently, it is important to monitor caregivers and patients with $\mathrm{ABI}$ after the acute phase and discharge from the hospital or rehabilitation center. $^{2,8,10,36}$

The findings of this study have important clinical and research implications. This study is one of the first large studies to investigate the relationship between respite care and wellbeing of caregivers and patients with ABI. The study highlights the satisfaction that patients with $\mathrm{ABI}$ and their caregivers have for activity day-care centers and emphasizes that more elaborate support is needed. Future studies should focus on the effect of respite care on both caregivers and patients. It may be useful to study the individual components and different types of respite care. Such studies would provide knowledge about the contribution of each component and the type of care to the well-being of caregivers and patients. There is a need for chronic care and support for patients with ABI and their caregivers. Such support should incorporate coping, mastery, and family components. 


\section{Study Limitations}

The present study was cross-sectional, and therefore the potential improvement of caregiver well-being as a result of respite care could not be studied. We did not consider whether caregivers made use of other intervention services, such as seeking psychological help. Caregivers who receive additional therapy may have better coping skills and thus experience less burden and higher life satisfaction. The day-care activity center is the most commonly used respite care facility by patients with ABI and their caregivers in The Netherlands. Although other services are provided, only this specific form of respite care was investigated in this study. Furthermore, of the investigated sample of patients with $\mathrm{ABI}, 70 \%$ were stroke patients, and ABI patients with aphasia were not represented in this sample. These limitations should be considered when generalizing our results to broader groups of patients with ABI. We developed the satisfaction with day-care activity center questionnaire specifically for this study. Therefore, no information on the reliability and validity of the scale is available. In addition, the caregiver and the patient received the questionnaires in the same envelope. Consequently, they may have influenced each other when completing the questionnaires.

\section{CONCLUSIONS}

From this study, we conclude that caregivers of patients with chronic ABI feel burdened and dissatisfied, despite their longterm participation in day-care activity centers. This study indicates that respite care alone is not sufficient in maintaining caregiver well-being. Caregiver well-being was not associated with the patients' injury severity, but with psychological characteristics (coping and mastery skills) of both caregivers and patients. Thus, these characteristics could be targets for interventions aiming to improve their well-being. Continuous and prolonged support is needed for both caregivers and patients after the initial injury.

\section{References}

1. van Exel NJ, Koopmanschap MA, van den Berg B, Brouwer WB, van den Bos GA. Burden of informal caregiving for stroke patients. Cerebrovasc Dis 2005;19:11-7.

2. Visser-Meily A, Post M, van de Port I, van Heugten C, van den Bos T. Psychosocial functioning of spouses in the chronic phase after stroke: improvement or deterioration between 1 and 3 years after stroke? Patient Educ Couns 2008;73:153-8.

3. Scholte op Reimer WJ, de Haan RJ, Rijnders PT, Limburg M, van den Bos GA. The burden of caregiving in partners of long-term stroke survivors. Stroke 1998;29:1605-11.

4. Sinnakaruppan I, Williams DM. Family carers and the adult head-injured: a critical review of carers' needs. Brain Inj 2001;15:653-72.

5. Chan J. Carers' perspective on respite for persons with acquired brain injury. Int J Rehabil Res 2007;30:137-46.

6. van Exel J, Moree M, Koopmanschap M, Goedheijt TS, Brouwer W. Respite care - an explorative study of demand and use in Dutch informal caregivers. Health Policy 2006;78:194-208.

7. Koopmanschap MA, van Exel NJ, van den Bos GA, van den Berg B, Brouwer WB. The desire for support and respite care: preferences of Dutch informal caregivers. Health Policy 2004; 68:309-20

8. Baumgarten M, Lebel P, Laprise H, Leclerc C, Quinn C. Adult day care for the frail elderly: outcomes, satisfaction, and cost. J Aging Health 2002;14:237-59.

9. McCann JJ, Hebert LE, Li Y, et al. The effect of adult day care services on time to nursing home placement in older adults with Alzheimer's disease. Gerontologist 2005;45:754-63.
10. Park YH. Day healthcare services for family caregivers of older people with stroke: needs and satisfaction. J Adv Nurs 2008;61:619-30.

11. van Exel J, de Graaf G, Brouwer W. Give me a break! Informal caregiver attitudes towards respite care. Health Policy 2008;88:73-87.

12. McNally S, Ben-Shlomo Y, Newman S. The effects of respite care on informal carers' well-being: a systematic review. Disabil Rehabil 1999;21:1-14.

13. Mason A, Weatherly H, Spilsbury K, et al. A systematic review of the effectiveness and cost-effectiveness of different models of community-based respite care for frail older people and their caregivers. Health Technol Assess 2007;11:1-157.

14. Shaw C, McNamara R, Abrams K, et al. Systematic review of respite care in the frail elderly. Health Technol Assess 2009;13:1-224.

15. Broadbent DE, Cooper PF, FitzGerald P, Parkes KR. The Cognitive Failures Questionnaire (CFQ) and its correlates. Br J Clin Psychol 1982;21:1-16

16. Ponds R, van Boxtel M, Jolles J. De 'Cognitive Failure Questionnaire' als maat voor subjectief cognitief functioneren. Tijdschrift voor Neuropsychiatrie 2006;1:37-45.

17. Wallace JC, Kass SJ, Stanny CJ. The Cognitive Failures Questionnaire revisited: dimensions and correlates. J Gen Psychol 2002;129:238-56.

18. van Swieten JC, Koudstaal PJ, Visser MC, Schouten HJ, van Gijn J. Interobserver agreement for the assessment of handicap in stroke patients. Stroke 1988;19:604-7.

19. Banks JL, Marotta CA. Outcomes validity and reliability of the Modified Rankin Scale: implications for stroke clinical trials. Stroke 2007;38:1091-6.

20. Pijfers EM, De Vries LA, Messing-Petersen H. Het Utrechts Communicatie Onderzoek. Westervoort: Stichting Afasie Nederland; 1985.

21. Fugl-Meyer AR, Branholm IB, Fugl-Meyer KS. Happiness and domain specific life satisfaction in adult northern Swedes. Clin Rehabil 1991;5:25-33.

22. Post MW, de Witte LP, van Asbeck FW, van Dijk AJ, Schrijvers AJ. Predictors of health status and life satisfaction in spinal cord injury. Arch Phys Med Rehabil 1998;79:395-401.

23. Visser-Meily A, Post M, Schepers V, Lindeman E. Spouses' quality of life 1 year after stroke: prediction at the start of clinical rehabilitation. Cerebrovasc Dis 2005;20:443-8.

24. Zigmond AS, Snaith RP. The Hospital Anxiety and Depression Scale. Acta Psychiatr Scand 1983;67:361-70.

25. Spinhoven P, Ormel J, Sloerkers PP, Kempen GI, Speckens AE, Van Hemert AM. A validation study of the Hospital Anxiety and Depression Scale (HADS) in different groups of Dutch subjects. Psychol Med 1997;27:363-70.

26. Robinson BC. Validation of a Caregiver Strain Index. J Gerontol 1983;38:344-8.

27. Schreurs PJG, van de Willige G, Tellegen B, Brosschot JF. The Utrecht Coping List: manual of the UCL. Lisse: Swets \& Zeitlinger; 1988.

28. Schreurs PJG, van de Willege G, Brosschot JF, Tellegen B, Graus GMH. De Utrechtse Coping Lijst: UCL: omgaan met problemen en gebeurtenissen. Utrecht: Swets en Zeitlinger; 1993.

29. Pearlin LI, Schooler C. The structure of coping. J Health Soc Behav 1978;19:2-21.

30. Cameron JI, Cheung AM, Streiner DL, Coyte PC, Stewart DE. Stroke survivors' behavioral and psychologic symptoms are associated with informal caregivers' experiences of depression. Arch Phys Med Rehabil 2006;87:177-83.

31. Chumbler NR, Rittman M, Van Puymbroeck M, Vogel WB, Qnin $\mathrm{H}$. The sense of coherence, burden, and depressive symptoms in informal caregivers during the first month after stroke. Int J Geriatr Psychiatry 2004;19:944-53.

32. van den Heuvel ET, de Witte LP, Schure LM, Sanderman R, Meyboom-de Jong B. Risk factors for burn-out in caregivers of 
stroke patients, and possibilities for intervention. Clin Rehabil 2001;15:669-77.

33. Visser-Meily A, Post M, van de Port I, Maas C, ForstbergWarleby G, Lindeman E. Psychosocial functioning of spouses of patients with stroke from initial inpatient rehabilitation to 3 years poststroke: course and relations with coping strategies. Stroke 2009;40:1399-404.

34. Forsberg-Wärleby G, Möller A, Blomstrand C. Life satisfaction in spouses of patients with stroke during the first year after stroke. J Rehabil Med 2004;36:4-11.
35. Backhaus SL, Ibarra SL, Klyce D, Trexler LE, Malec JF. Brain injury coping skills group: a preventative intervention for patients with brain injury and their caregivers. Arch Phys Med Rehabil 2010;91:840-8

36. Visser-Meily JM, van den Bos GA, Kappelle LJ. Better acute treatment induces more investments in chronic care for stroke patients. Int J Stroke 2009;4:352-3.

\section{Supplier}

a. SPSS Inc, 233 S Wacker Dr, 11th Fl, Chicago, IL 60606. 